\title{
Article \\ Factors Associated with Nutritional Deficiency Biomarkers in Candidates for Bariatric Surgery: A Cross-Sectional Study in a Peruvian High-Resolution Clinic
}

\author{
Adrian Riva-Moscoso ${ }^{1}$, Raisa N. Martinez-Rivera ${ }^{2}$, Gianfranco Cotrina-Susanibar ${ }^{3}$ (D), \\ Fortunato S. Príncipe-Meneses ${ }^{1}$, Diego Urrunaga-Pastor ${ }^{4, * \mathbb{D}}$, Gustavo Salinas-Sedo 5 \\ and Carlos J. Toro-Huamanchumo ${ }^{5,6, *(D)}$
}

1 Escuela de Medicina, Universidad Peruana de Ciencias Aplicadas, Lima 15067, Peru; u201612662@upc.edu.pe (A.R.-M.); u201613482@upc.edu.pe (F.S.P.-M.)

2 Facultad de Ciencias de la salud, Escuela Profesional de Medicina Humana, Universidad Nacional de Piura, Piura 20002, Peru; 0902016031@alumnos.unp.edu.pe

3 Escuela de Medicina Humana, Universidad Católica Santo Toribio de Mogrovejo, Chiclayo 14012, Peru; 72114110@usat.edu.pe

4 Facultad de Ciencias de la Salud, Universidad Científica del Sur, Carrera de Medicina Humana, Lima 15067, Peru

5 Unidad de Investigación Multidisciplinaria, Clínica Avendaño, Lima 15074, Peru; gsalinas@clinicaavendanoperu.com

6 Unidad para la Generación y Síntesis de Evidencias en Salud, Universidad San Ignacio de Loyola, Lima 15012, Peru

check for updates

Citation: Riva-Moscoso, A.; Martinez-Rivera, R.N.;

Cotrina-Susanibar, G.;

Príncipe-Meneses, F.S.;

Urrunaga-Pastor, D.; Salinas-Sedo, G.; Toro-Huamanchumo, C.J. Factors Associated with Nutritional Deficiency Biomarkers in Candidates for Bariatric Surgery: A

Cross-Sectional Study in a Peruvian High-Resolution Clinic. Nutrients 2022, 14, 82. https://doi.org/ $10.3390 /$ nu14010082

Received: 16 November 2021 Accepted: 21 December 2021 Published: 25 December 2021

Publisher's Note: MDPI stays neutral with regard to jurisdictional claims in published maps and institutional affiliations.

Copyright: (C) 2021 by the authors. Licensee MDPI, Basel, Switzerland. This article is an open access article distributed under the terms and conditions of the Creative Commons Attribution (CC BY) license (https:// creativecommons.org/licenses/by/ $4.0 /)$.

* Correspondence: durrunaga@cientifica.edu.pe (D.U.-P.); ctoro@usil.edu.pe (C.J.T.-H.)

\begin{abstract}
Previous studies have described multiple nutritional deficiencies after bariatric surgery (BS). However, few studies have evaluated these deficiencies prior to BS, specifically in Latin America. This study aimed to determine the factors associated with nutritional deficiency biomarkers in candidates for BS in Peru. We included adults of both sexes, aged 18 to 59 years, admitted to a Peruvian clinic with a body mass index $(\mathrm{BMI}) \geq 30 \mathrm{~kg} / \mathrm{m}^{2}$; they were candidates for BS from 2017 to 2020. We considered the serum levels of hemoglobin and albumin (in tertiles) as the nutritional deficiency biomarkers. In order to assess the associated factors, we calculated crude (cPR) and adjusted prevalence ratios (aPR) with their respective $95 \%$ confidence intervals $(95 \% \mathrm{CI})$. We analyzed 255 patients: $63.1 \%$ were males, with a mean age of $37.1 \pm 10.3$ years and mean hemoglobin and albumin values of $14.0 \pm 1.5 \mathrm{~g} / \mathrm{dL}$ and $4.6 \pm 0.4 \mathrm{~g} / \mathrm{dL}$, respectively. We found that males $(\mathrm{aPR}=1.86$; 95\%CI: $1.26-2.73 ; p=0.002)$, participants between 30 and $49(\mathrm{aPR}=2.02 ; 95 \% \mathrm{CI}: 1.24-3.28 ; p=0.004)$ or 50 years or more $(\mathrm{aPR}=2.42 ; 95 \% \mathrm{CI}$ : $1.35-4.35 ; p=0.003)$, participants with a BMI $\geq 40 \mathrm{~kg} / \mathrm{m}^{2}$ $(\mathrm{aPR}=1.68 ; 95 \% \mathrm{CI}: 1.09-2.60 ; p=0.018)$, participants with impaired high-density lipoprotein levels $(\mathrm{aPR}=1.43 ; 95 \% \mathrm{CI}: 1.01-2.05 ; p=0.049)$ and individuals in the high tertile of $\mathrm{C}$-reactive protein $(\mathrm{aPR}=6.94 ; 95 \% \mathrm{CI}: 3.37-14.32 ; p<0.003)$ had a higher probability of being in the lower tertile of albumin. In addition, we found that the male sex ( $\mathrm{aPR}=6.94 ; 95 \% \mathrm{CI}$ : 3.37-14.32; $p<0.001)$ and elevated cholesterol levels ( $\mathrm{aPR}=0.71 ; 95 \% \mathrm{CI}$ : 0.52-0.97; $p=0.034$ ) were associated with the lowest hemoglobin tertile. In our setting, nutritional deficiency biomarkers were associated with sociodemographic, anthropometric and laboratory markers. The pre-bariatric surgery correction of nutritional deficiencies is essential, and can prevent major complications after surgery.
\end{abstract}

Keywords: obesity; bariatric surgery; nutrition; nutritional assessment

\section{Introduction}

The prevalence of obesity tripled between 1975 and 2016. In 2016, it was estimated that $39 \%$ of adults worldwide had overweight, and $13 \%$ had obesity [1]. Obesity represents a public health problem due to its association with diseases such as high blood pressure, type 2 diabetes mellitus, cardiovascular diseases, and cancer [2]. Over the years, obesity 
has ceased to represent a problem only in people at a high socioeconomic level [2], as the burden of obesity has been increasing, and is unevenly distributed in all socioeconomic groups. Among individuals with low resources, obesity is associated with a greater number of comorbidities compared to those with medium or high incomes, further driving health inequities, and requiring the development of national public policies to prevent and treat obesity-related disease [3].

Bariatric surgery is currently the best alternative to combat morbid obesity, providing better control of chronic diseases, a considerable decrease in weight, and long-term weightloss maintenance, improving quality of life and decreasing mortality [4]. Furthermore, the demand for this procedure has increased in recent years. In 2016, it was estimated that 685,874 bariatric surgery interventions were carried out worldwide [5]. Likewise, according to the latest data, in 2017 a total of 228,000 bariatric procedures were reported in the United States [6]. Despite the benefits of these interventions [4], as with any procedure, complications can occur, some of which are related to the procedure, such as gallstones, marginal ulceration, internal hernia and intussusception [7]. Likewise, the anatomical and physiological alteration of the gastrointestinal tract produced by surgery makes the patient more susceptible to disabling diseases such as anemia, protein malnutrition, deficiencies of calcium and vitamin D micronutrients, low serum levels of other fat-soluble vitamins, and essential mineral deficiencies including magnesium, zinc, copper, and selenium [8].

Previous studies carried out in United States and Europe [9-13] evaluated nutritional deficiencies in patients after undergoing bariatric surgery, with an average post-surgery follow-up ranging from 12 to 24 months. On the other hand, nutritional deficiencies have been explored less frequently in patients who are candidates for bariatric surgery [14-18], and even less so in Latin America [19]. It is relevant to obtain information related to nutritional deficiency biomarkers prior to bariatric surgery, and to identify the associated factors in order to explore the conditions that could improve later outcomes, given the greater influx of patients who are interested in undergoing bariatric surgery in Peru [20]. In addition, the evidence generated could serve as the basis to better understand the baseline status of patients undergoing bariatric surgery, to provide better preparation and medical care before and after surgery, and thus to prevent [14] the consequences of these deficiencies in the long term, which can lead to more serious scenarios for the patient.

Therefore, our study aimed to explore these deficiencies in patients who were candidates for bariatric surgery at a high-resolution private clinic in Lima, Peru.

\section{Materials and Methods}

\subsection{Study Design and Context}

We performed a secondary analysis of the database for epidemiological surveillance purposes created by a private clinic in Lima, Peru. This private clinic is a high-resolution center specialized in the treatment of obesity and metabolic and nutritional diseases. This center performed in 2021 more than 700 bariatric surgeries, including sleeve gastrectomies and gastric bypass.

\subsection{Study Population}

We included adults of both sexes between 18 and 59 years old with a body mass index (BMI) greater than or equal to $30 \mathrm{~kg} / \mathrm{m}^{2}$ who attended the private clinic and qualified as candidates for a surgical procedure as treatment for obesity from 2017 to 2020 . We excluded pregnant women, participants self-reporting harmful alcohol intake, a history of acute myocardial infarction or findings consistent with myocardial ischemia according to an electrocardiogram, a history of viral hepatitis (hepatitis B and C), autoimmune liver diseases, liver deposition diseases (hemochromatosis, hemosiderosis, and the chronic use of drugs that can induce secondary non-alcoholic steatohepatitis: amiodarone, tamoxifen, methotrexate, corticosteroids, valproate and nitrofurantoin), and patients with a liver biopsy with less than 10 portal spaces and/or a depth less than $5 \mathrm{~mm}$. They were excluded because this could represent potential confounders, according to the literature. 


\subsection{Outcomes}

We considered hemoglobin and albumin as nutritional deficiency biomarkers. Similarly, to previous studies, these laboratory markers were analyzed as tertiles [21,22]. The hemoglobin sample was collected in tubes containing ethylenediaminetetraacetic acid for complete blood count tests, while the bromocresol green colorimetric assay was used for albumin.

\subsection{Independent Variables}

\subsubsection{Sociodemographic Characteristics}

We considered the following sociodemographic variables: sex (female, male) and age (18 to 29 years, 30 to 49 , and 50 and over).

\subsubsection{Medical and Personal History}

We included comorbidities including hypertension (no, yes), type 2 diabetes mellitus (no, yes) and hypothyroidism (no, yes). In addition, we assessed smoking habits (no, yes) in the participants through self-reporting.

\subsubsection{Laboratory and Anthropometric Markers}

We evaluated the lipid profile in the participants, including cholesterol (defined as being elevated at a value greater than or equal to $200 \mathrm{mg} / \mathrm{dL}$ ), triglycerides (defined as being elevated at a value greater than or equal to $150 \mathrm{mg} / \mathrm{dL}$ ), high-density lipoprotein (HDL) (defined as being altered with a value less than $40 \mathrm{mg} / \mathrm{dL}$ in men, or less than $50 \mathrm{mg} / \mathrm{dL}$ in women), and low-density lipoprotein (LDL) (defined as being altered with a value greater than or equal to $130 \mathrm{mg} / \mathrm{dL}$ ). We calculated the Homeostatic Model Assessment for Insulin Resistance (HOMA-IR) in $\mathrm{mg} / \mathrm{dL}$ using the following formula: (glucose $\times$ insulin)/405. The body mass index (BMI) was calculated using the following formula: weight $(\mathrm{kg}) /[\text { height }(\mathrm{m})]^{2}$; it was then categorized as $30-34.99 \mathrm{~kg} / \mathrm{m}^{2}, 35-39.99$, or 40 or more. The $\mathrm{C}$-reactive protein values were considered altered with values greater than $10 \mathrm{mg} / \mathrm{L}$. Nonalcoholic fatty liver disease (NAFLD) was diagnosed by the histopathological examination of liver biopsy taken during surgery. All of the liver biopsies were reviewed by two experienced pathologists.

\subsection{Statistical Analysis}

We performed the statistical analysis using the statistical package STATA v14 (StataCorp, College Station, TX, USA). The descriptive analysis of the quantitative variables was presented using measures of central tendency and dispersion, as appropriate, after evaluating their normality. The variables with a normal distribution were presented as means and standard deviation, and those with a non-normal distribution were expressed as a median and interquartile range (IQR). On the other hand, the qualitative variables were described using relative and absolute frequencies.

The bivariate analyses of the tertiles of the nutritional deficiency biomarkers and the qualitative covariates of interest were performed using the Chi-square test or Fisher's exact test, depending on the expected values. Likewise, we used the ANOVA or Kruskal Wallis test to compare the numerical variables among the tertiles of the outcome variables. We constructed generalized linear models of the Poisson family with logarithmic link function and robust variances to evaluate the factors associated with the nutritional deficiency biomarkers in the study sample. For the multivariable analysis, the tertiles of the nutritional deficiency biomarkers were dichotomized, and the association measure was calculated for the tertile of greater clinical relevance. The forward manual selection method was used to select the factors associated with the outcome variables. We calculated the crude (cPR) and adjusted (aPR) prevalence ratios with their respective $95 \%$ confidence intervals (95\%CI). A $p$ value $<0.05$ was considered statistically significant.

We decided not to stratify by sex, as we tested for interaction with the log-likelihood ratio test, and obtained a $p$-value $>0.05$. 


\subsection{Ethics}

The present study was approved by the Institutional Review Board of the Clínica Avendaño (010-2021-CIEI). Participant consent was not required, and the study database was anonymized.

\section{Results}

\subsection{Characteristics of the Study Sample}

We included 255 patients with a mean age of $37.1 \pm 10.3$ years who were candidates for bariatric surgery. We found that $63.1 \%(n=161)$ were male, and only $12.9 \%(n=33)$ were 50 years or older. Furthermore, $18.4 \%(n=47)$ had hypertension, while $6.3 \%(n=16)$ and $11.0 \%(n=28)$ had type 2 diabetes mellitus and hypothyroidism, respectively. Furthermore, in relation to the lipid profile, $42.3 \%(n=108)$ had elevated cholesterol levels, and $58.4 \%$ $(n=149)$ had altered HDL values. We found that the mean HOMA-IR was $6.4 \pm 4.5$ units; $96.5 \%(n=246)$ of patients had NAFLD, $72.1 \%(n=184)$ had a BMI greater than or equal to $35 \mathrm{~kg} / \mathrm{m}^{2}$, and the median CRP was 6.1 units (IQR: 3.1-10.2) (Table 1). On the other hand, the mean hemoglobin and albumin values were $14.0 \pm 1.5$ and $4.6 \pm 0.4$, respectively (Table 2).

Table 1. Demographic characteristics, medical history, and laboratory and clinical markers of the study sample $(n=255)$.

\begin{tabular}{|c|c|}
\hline Characteristics & $n(\%)$ \\
\hline \multicolumn{2}{|l|}{ Sex } \\
\hline Female & $94(36.9 \%)$ \\
\hline Male & $161(63.1 \%)$ \\
\hline Age & $37.1 \pm 10.3^{*}$ \\
\hline 18 to 29 years & $66(25.9)$ \\
\hline 30 to 49 & $156(61.2)$ \\
\hline 50 or over & $33(12.9)$ \\
\hline \multicolumn{2}{|l|}{ Hypertension } \\
\hline No & $208(81.6 \%)$ \\
\hline Yes & $47(18.4 \%)$ \\
\hline \multicolumn{2}{|c|}{ Type 2 diabetes mellitus } \\
\hline No & $239(93.7 \%)$ \\
\hline Yes & $16(6.3 \%)$ \\
\hline \multicolumn{2}{|l|}{ Hypothyroidism } \\
\hline No & $227(89.0 \%)$ \\
\hline Yes & $28(11.0 \%)$ \\
\hline \multicolumn{2}{|l|}{ Smoking habit } \\
\hline No & $195(76.5 \%)$ \\
\hline Yes & $60(23.5 \%)$ \\
\hline Cholesterol & $194.2 \pm 38.8^{*}$ \\
\hline Normal & $147(57.7)$ \\
\hline Elevated & $108(42.3)$ \\
\hline Triglycerides & $151(112-207) * *$ \\
\hline Normal & $131(51.4)$ \\
\hline Elevated & $124(48.6)$ \\
\hline HDL & $43.8 \pm 11.5 *$ \\
\hline Normal & $106(41.6)$ \\
\hline Altered & $149(58.4)$ \\
\hline LDL & $116.2 \pm 33.8^{*}$ \\
\hline Normal & $90(35.3)$ \\
\hline Altered & $165(64.7)$ \\
\hline
\end{tabular}


Table 1. Cont.

\begin{tabular}{cc}
\hline Characteristics & $\boldsymbol{n} \mathbf{( \% )}$ \\
\hline CRP & $6.1(3.1-10.2)^{*}$ \\
Low tertile & $2.5(1.8-3.1)^{* *}$ \\
Intermediate tertile & $6.2(5.0-7.4)^{* *}$ \\
High tertile & $12.7(10.2-16.9)^{* *}$ \\
HOMA-IR & $6.4 \pm 4.5^{*}$ \\
NAFLD & \\
No & $9(3.5)$ \\
Yes & $246(96.5)$ \\
Body mass index & $38.7 \pm 5.6^{*}$ \\
30-34.99 kg/m $\mathrm{m}^{2}$ & $71(27.9)$ \\
$35-39.99$ & $97(38.0)$ \\
40 or over & $87(34.1)$
\end{tabular}

${ }^{*}$ Mean \pm standard deviation. ${ }^{* *}$ Median (interquartile range). HDL: high-density lipoprotein; LDL: low-density lipoprotein; NAFLD: nonalcoholic fatty liver disease; CRP: C-reactive protein.

Table 2. Tertiles of the nutritional deficiency biomarkers in the study sample $(n=255)$.

\begin{tabular}{cc}
\hline Biomarker & Mean \pm Standard Deviation \\
\hline Hemoglobin & $14.0 \pm 1.5$ \\
Low tertile & $12.5 \pm 0.9$ \\
Intermediate tertile & $14.0 \pm 0.3$ \\
High tertile & $15.7 \pm 0.8$ \\
Albumin & $4.6 \pm 0.4$ \\
Low tertile & $4.2 \pm 0.2$ \\
Intermediate tertile & $4.6 \pm 0.1$ \\
\hline
\end{tabular}

\subsection{Bivariate Analysis According to the Tertiles of Albumin and Hemoglobin}

We found differences with HDL, NAFLD, BMI categories and CRP tertiles with respect to the albumin tertiles. Likewise, we found differences between sex, hypothyroidism, and triglyceride and HDL values compared to the tertiles of hemoglobin. Furthermore, we found a higher median HOMA-IR in the participants in the upper hemoglobin tertile compared to the other two tertiles ( 6.2 vs. 5.6 vs. $4.5 ; p<0.001$ ). Table 3 shows the results of the bivariate analysis between the covariates and the outcomes of interest.

Table 3. Bivariate analysis of the demographic characteristics, medical history, laboratory and clinical markers, and outcomes of interest in the study sample.

\begin{tabular}{|c|c|c|c|c|c|c|c|c|}
\hline \multirow[b]{2}{*}{ Characteristics } & \multicolumn{4}{|c|}{ Albumin } & \multicolumn{4}{|c|}{ Hemoglobin } \\
\hline & $\begin{array}{l}\text { Low Tertile } \\
\quad(n=85)\end{array}$ & $\begin{array}{c}\text { Intermediate } \\
\text { Tertile } \\
(n=85)\end{array}$ & $\begin{array}{l}\text { High Tertile } \\
\quad(n=85)\end{array}$ & $p$ Value & $\begin{array}{l}\text { Low Tertile } \\
\quad(n=88)\end{array}$ & $\begin{array}{c}\text { Intermediate } \\
\text { Tertile } \\
(n=85)\end{array}$ & $\begin{array}{l}\text { High Tertile } \\
\quad(n=82)\end{array}$ & $p$ Value \\
\hline Sex & & & & 0.159 & & & & $<0.001$ \\
\hline Female & $25(26.6)$ & $37(39.4)$ & $32(34.0)$ & & $7(7.5)$ & $19(20.2)$ & $68(72.3)$ & \\
\hline Male & $60(37.3)$ & $48(29.8)$ & $53(32.9)$ & & $81(50.3)$ & $66(41.0)$ & $14(8.7)$ & \\
\hline Age & & & & 0.064 & & & & 0.741 \\
\hline 18 to 29 years & $14(21.1)$ & $25(37.9)$ & $27(40.9)$ & & $23(34.9)$ & $23(34.9)$ & $20(30.2)$ & \\
\hline 30 to 49 & $57(36.5)$ & $47(30.1)$ & $52(33.3)$ & & $56(35.9)$ & $52(33.3)$ & $48(30.8)$ & \\
\hline 50 or over & $14(42.4)$ & $13(39.4)$ & $6(18.2)$ & & $9(27.3)$ & $10(30.3)$ & $14(42.4)$ & \\
\hline Hypertension & & & & 0.279 & & & & 0.086 \\
\hline No & $65(31.3)$ & $70(33.7)$ & $73(35.1)$ & & $77(37.0)$ & $70(33.7)$ & $61(29.3)$ & \\
\hline Yes & $20(42.6)$ & 15 (31.9) & $12(25.5)$ & & $11(23.4)$ & $15(31.9)$ & $21(44.7)$ & \\
\hline $\begin{array}{c}\text { Type } 2 \text { diabetes } \\
\text { mellitus }\end{array}$ & & & & 0.627 & & & & 0.099 \\
\hline No & $78(32.6)$ & $80(33.5)$ & $81(33.9)$ & & $84(35.2)$ & $82(34.3)$ & $73(30.5)$ & \\
\hline Yes & $7(43.8)$ & $5(31.2)$ & $4(25.0)$ & & $4(25.0)$ & $3(18.8)$ & $9(56.2)$ & \\
\hline Hypothyroidism & & & & 0.594 & & & & 0.040 \\
\hline
\end{tabular}


Table 3. Cont.

\begin{tabular}{|c|c|c|c|c|c|c|c|c|}
\hline \multirow[b]{2}{*}{ Characteristics } & \multicolumn{4}{|c|}{ Albumin } & \multicolumn{4}{|c|}{ Hemoglobin } \\
\hline & $\begin{array}{l}\text { Low Tertile } \\
\quad(n=85)\end{array}$ & $\begin{array}{c}\text { Intermediate } \\
\text { Tertile } \\
(n=85)\end{array}$ & $\begin{array}{l}\text { High Tertile } \\
\quad(n=85)\end{array}$ & $p$ Value & $\begin{array}{l}\text { Low Tertile } \\
\quad(n=88)\end{array}$ & $\begin{array}{c}\text { Intermediate } \\
\text { Tertile } \\
(n=85)\end{array}$ & $\begin{array}{l}\text { High Tertile } \\
\quad(n=82)\end{array}$ & $p$ Value \\
\hline No & 75 (33.0) & $74(32.6)$ & $78(34.4)$ & & $73(32.1)$ & $76(33.5)$ & $78(34.4)$ & \\
\hline Yes & $10(35.7)$ & $11(39.3)$ & $7(25.0)$ & & 15 (53.6) & $9(32.1)$ & $4(14.3)$ & \\
\hline Smoking habit & & & & 0.253 & & & & 0.689 \\
\hline No & 66 (33.9) & $60(30.8)$ & $69(35.4)$ & & $69(35.4)$ & $66(33.8)$ & $60(30.8)$ & \\
\hline Yes & $19(31.7)$ & $25(41.7)$ & $16(26.7)$ & & $19(31.7)$ & $19(31.7)$ & $22(36.7)$ & \\
\hline Cholesterol & & & & 0.364 & & & & 0.371 \\
\hline Normal & 54 (36.7) & 48 (32.7) & 45 (30.6) & & $56(38.1)$ & 46 (31.3) & 45 (30.6) & \\
\hline Elevated & $31(28.7)$ & $37(34.3)$ & $40(37.0)$ & & $32(29.6)$ & $39(36.1)$ & $37(34.3)$ & \\
\hline Triglycerides & & & & 0.815 & & & & 0.012 \\
\hline Normal & $46(35.1)$ & $42(32.1)$ & $43(32.8)$ & & $51(38.9)$ & $49(37.4)$ & 31 (23.7) & \\
\hline Elevated & 39 (31.5) & $43(34.7)$ & $42(33.9)$ & & $37(29.8)$ & $36(29.0)$ & $51(41.1)$ & \\
\hline HDL & & & & 0.025 & & & & $<0.001$ \\
\hline Normal & $33(31.1)$ & $28(26.4)$ & 45 (42.5) & & $51(48.1)$ & $39(36.8)$ & $16(15.1)$ & \\
\hline Altered & $52(34.9)$ & 57 (38.3) & $40(26.8)$ & & $37(24.8)$ & $46(30.9)$ & $66(44.3)$ & \\
\hline LDL & & & & 0.697 & & & & 0.115 \\
\hline Normal & $32(35.6)$ & $31(34.4)$ & $27(30.0)$ & & $38(42.2)$ & $29(32.2)$ & $23(25.6)$ & \\
\hline Altered & $53(32.1)$ & 54 (32.7) & $58(35.2)$ & & $50(50.3)$ & 56 (33.9) & 59 (35.8) & \\
\hline HOMA-IR & $5.7(3.6-8.5) *$ & $5.3(3.2-6.8)$ * & $5.1(3.4-8.3)$ * & 0.183 & $4.5(3.5-5.9)$ * & $5.6(3.2-7.7) *$ & $6.2(4.3-9.8)$ * & $<0.001$ \\
\hline NAFLD & & & & 0.046 & & & & 0.758 \\
\hline No & $3(33.3)$ & $6(67.7)$ & $0(0)$ & & $4(44.4)$ & $3(33.3)$ & $2(22.2)$ & \\
\hline Yes & $82(33.3)$ & 79 (32.1) & 85 (34.6) & & $84(34.2)$ & $82(33.3)$ & $80(32.5)$ & \\
\hline Body mass index & & & & $<0.001$ & & & & 0.303 \\
\hline $30-34.99 \mathrm{~kg} / \mathrm{m}^{2}$ & $19(26.8)$ & $22(31.0)$ & $30(42.2)$ & & $30(42.3)$ & $24(33.8)$ & 17 (23.9) & \\
\hline $35-39.99$ & $21(21.7)$ & $42(43.3)$ & $34(35.1)$ & & $32(33.0)$ & $34(35.0)$ & $31(32.0)$ & \\
\hline 40 or over & 45 (51.7) & $21(24.1)$ & $21(24.1)$ & & $26(29.9)$ & $27(31.0)$ & $34(39.1)$ & \\
\hline CRP & & & & $<0.001$ & & & & 0.377 \\
\hline Low tertile & $18(20.9)$ & $33(38.4)$ & $35(40.7)$ & & $30(34.8)$ & $28(32.6)$ & $28(32.6)$ & \\
\hline $\begin{array}{l}\text { Intermediate } \\
\text { tertile }\end{array}$ & $22(26.2)$ & $30(35.7)$ & $32(38.1)$ & & $25(29.7)$ & $26(31.0)$ & $33(39.3)$ & \\
\hline High tertile & 45 (52.9) & $22(25.9)$ & $18(21.2)$ & & $33(38.8)$ & $31(36.5)$ & $21(24.7)$ & \\
\hline
\end{tabular}

* Median (interquartile range). HDL: high-density lipoprotein; LDL: low-density lipoprotein; NAFLD: nonalcoholic fatty liver disease; CRP: C-reactive protein.

\subsection{Factors Associated with Nutritional Deficiency Biomarkers in the Study Sample}

We found that men $(\mathrm{aPR}=1.86 ; 95 \% \mathrm{CI}: 1.26-2.73 ; p=0.002)$, participants with an age between 30 and 49 ( $\mathrm{aPR}=2.02$; 95\%CI: 1.24-3.28; $p=0.004)$ and those aged 50 years or more $(\mathrm{aPR}=2.42 ; 95 \% \mathrm{CI}: 1.35-4.35 ; p=0.003)$ were more likely to be in the lower tertile of albumin. In addition, the participants with a BMI of $40 \mathrm{~kg} / \mathrm{m}^{2}$ or more $(\mathrm{aPR}=1.68 ; 95 \% \mathrm{CI}$ : $1.09-2.60$; $p=0.018)$, with altered HDL levels ( $\mathrm{aPR}=1.43 ; 95 \% \mathrm{CI}: 1.01-2.05 ; p=0.049)$ and high CRP values $(\mathrm{aPR}=1.83 ; 95 \% \mathrm{CI}: 1.13-2.96 ; p=0.013)$ were associated with a higher prevalence of being in the lower albumin tertile. Men $(\mathrm{aPR}=6.94 ; 95 \% \mathrm{CI}$ : 3.37-14.32; $p<0.001)$ had a greater probability of being in the lower hemoglobin tertile, while individuals with high cholesterol levels ( $\mathrm{aPR}=0.71$; 95\%CI: 0.52-0.97; $p=0.034$ ) had a lower prevalence (Table 4 ). 
Table 4. Generalized linear models of the Poisson family with the log link function and robust variances to evaluate the factors associated with nutritional deficit markers in the study sample.

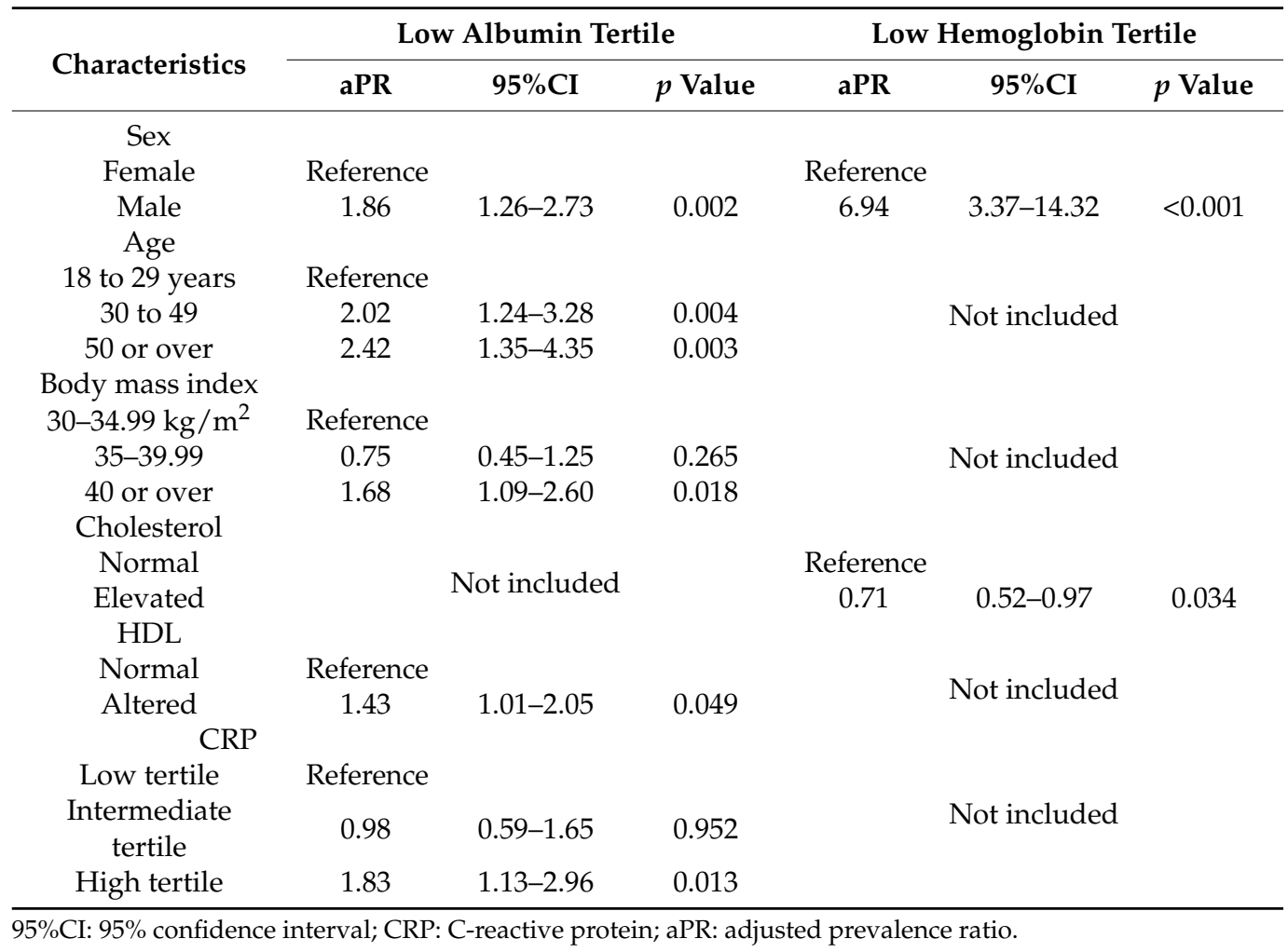

\section{Discussion}

\subsection{Main Findings}

In this study of 255 adult candidates for bariatric surgery, several factors were found to be associated with nutritional deficiency biomarkers. Male sex, ages of over 30 years, a BMI greater than or equal to $40 \mathrm{~kg} / \mathrm{m}^{2}$, altered HDL levels, and being in the high-CRP tertile were associated with having low albumin levels. In addition, males were associated with a higher probability of having low hemoglobin levels, while a higher cholesterol level was associated with a lower probability of having low hemoglobin levels. Although the factors associated with nutritional deficiency have been studied, most were explored in patients after they had undergone bariatric surgery [23-27]. To our knowledge, this is one of the first studies carried out in a Latin American population, and it provides novel and interesting information on the subject.

\subsection{Comparison with Previous Studies}

Although most previous studies have evaluated the determinants of nutritional deficiency in patients following bariatric surgery, in the last decade, there has been greater interest in the evaluation of nutritional deficiency in patients who are candidates for bariatric surgery $[15,16,18,19,28]$. However, most of these studies were carried out in European [15,16], Asian [17] and North American [18] populations.

In a study carried out in Spain [16] in 115 female patients who were candidates for bariatric surgery, it was found that $6.1 \%$ had hypoalbuminemia and $2.6 \%$ had hemoglobin values less than $12 \mathrm{~g} / \mathrm{dL}$. In addition, another study carried out in Germany, in patients with morbid obesity [15], found that $88 \%$ had low serum albumin results $(<40 \mathrm{~g} / \mathrm{dL})$, describing an association between morbid obesity and a low consumption of essential micronutrients. On the other hand, a study carried out in South Korea [17] evaluated 215 patients who were candidates for bariatric surgery, and reported mean hemoglobin 
values for both sexes of $14.5 \mathrm{~g} / \mathrm{dL}$; however, the prevalence of anemia differed between men and women, with $1.3 \%$ and $7.4 \%$, respectively.

Most of the studies conducted in Latin America evaluated nutritional deficiencies after bariatric surgery [29]. However, a previous study carried out in Chile [19] evaluated nutritional deficiencies in 103 women, including the measurement of albumin, hemoglobin, ferritin, and vitamins and minerals such as selenium and zinc. In addition, it included measurements such as dual-energy X-ray absorptiometry (DEXA) and eating habits. Our study included people of both sexes, and the sample was larger. Indeed, our study provides relevant information on the Peruvian population.

\subsection{Interpretation of the Results}

We found that being over 30 years of age was associated with a higher probability of being in the lower tertile of albumin. Preoperative hypoalbuminemia has been identified as a modifiable factor which is predictive of serious complications in bariatric surgery candidates [30]. An inverse relationship has been described between age and serum albumin, and we more frequently find older adult patients with hypoalbuminemia [31]. In a cohort in which the participants had a mean age of 34.8 years, the mean albumin values were $4.1 \mathrm{~g} / \mathrm{dL}$ one year after the intervention, and $4.3 \mathrm{~g} / \mathrm{dL}$ after 3 years [32]. Similarly, other studies have shown that age is not a cause of hypoalbuminemia; rather, this marker is a risk factor of mortality [33]. The inflammatory state and, particularly, high interleukin-6 and tumor necrosis factor (TNF)-alpha concentrations are the two main markers associated with hypoalbuminemia [33].

Likewise, we found that having altered HDL values was associated with a greater probability of being in the lower albumin tertile. To our knowledge, no previous study has described a similar association in patients who are candidates for bariatric surgery. This finding could be important for two reasons. First, a previous study found that the HDL values in candidates for bariatric surgery improved after surgery, suggesting its benefit [34] As such, this variable could be useful as a potential marker of a successful metabolic status after surgery. Second, because HDL was associated with the lower albumin tertile, this lipid marker could be important to predict hypoalbuminemia in candidates, and therefore these patients could be considered to receive nutritional support.

We found that a BMI greater than or equal to $40 \mathrm{~kg} / \mathrm{m}^{2}$ was associated with a greater probability of having low albumin values. In a study conducted in China, the prevalence of hypoalbuminemia in candidates for bariatric surgery was $11.8 \%$ [35]. These authors also found a statistically significant association between elevated BMI levels and serum albumin deficiency. The patients with a BMI of $40-45$ and $>45 \mathrm{~kg} / \mathrm{m}^{2}$ had a prevalence of hypoalbuminemia of $12.8 \%$ and $30.3 \%$, respectively [35]. One possible explanation for this finding is the difference in races or complex mechanisms not yet identified between BMI and albumin values. Another possible explanation could be the state of chronic inflammation represented by obesity, in which adipocyte hypertrophy and hypoxia lead to the production of pro-inflammatory cytokines, such as TNF-alpha. It is plausible that this state of inflammation could lead to altered serum albumin levels among patients with obesity [36].

On the other hand, we found an association between the high tertile of CRP and low albumin values in the participants of the study sample. This finding is consistent with that described in Italy, in which candidates for bariatric surgery with low levels of albumin were more likely to be in the group with high levels of CRP (with a mean of $7.7 \mathrm{mg} / \mathrm{L}$ ). This is generally due to the chronic pro-inflammatory state of patients with obesity, which results in an increase in acute-phase proteins such as CRP, as well as a decrease in albumin concentrations [37], both of which are clinical markers of inflammation. The finding of hypoalbuminemia should be interpreted with caution because, in inflammatory stages, albumin tends to decrease, and thereby overlap its true value [37].

In our study, male sex was associated with lower hemoglobin levels. A previous study showed that the high prevalence of anemia could be due to the lack of access to iron-rich 
foods and a lack of adherence to oral iron treatment due to its adverse gastrointestinal effects. However, the highest prevalence of anemia was found in females $(21.6 \%)$, most likely due to the large number of women of reproductive age included in the study [14]; this result was also evidenced in another similar study carried out in South Korea [17]. On the other hand, a high cholesterol level was associated with low hemoglobin levels in the study sample. In a retrospective study analyzing the nutritional profile of patients who had undergone bariatric surgery in Brazil [38], the preoperative prevalence of low hemoglobin levels was $6.5 \%$, while the prevalence of altered cholesterol levels was $54.7 \%$. It should be noted that in the follow-up 7 to 10 years after undergoing bariatric surgery, the number of patients with hypercholesterolemia in Chile [39] reduced by $88 \%$, while the prevalence of anemia in these patients remained at $31 \%$. However, this association may not be clinically relevant, and could be due to a spurious association. Therefore, it has to be corroborated by future studies.

\subsection{Clinical Practice Relevance}

Most studies focus on post-bariatric surgery results, while we reported the results of patients who were candidates for bariatric surgery. These findings could help to avoid major complications after surgery, with timely actions in the highest risk group. The role of albumin as a nutritional biomarker has been described previously, specifically in patients undergoing abdominal surgery [40]. Likewise, the evaluation of hemoglobin as a marker of malnutrition was proposed in a previous study. Additionally, the authors concluded that its evaluation is even more useful in older adults [41].

The correction of low hemoglobin values is a challenge which can lead to a reduction in future complications, with previous studies reporting the development of anemia in around $15 \%$ of post-bariatric surgery patients. Likewise, $20 \%$ of these individuals fail to recover after 1 year of follow-up [42]. Moreover, in this latter study, women presented the lowest hemoglobin levels, probably due to blood loss during the menstrual cycle.

Furthermore, serum albumin levels can be used as a prognostic tool to help predict the medical and surgical outcomes of the patient. The association of low albumin levels with adverse patient outcomes is due to the fact that albumin is a biomarker of severe protein malnutrition. Likewise, it has been reported that the preoperative detection of hypoalbuminemia was associated with adverse outcomes, specifically delayed wound healing, poor surgical outcomes, the need for repeated surgery, and higher readmission rates [36]. Therefore, the consumption of foods rich in protein (eggs, fish, meat, soy products, and legumes) and the reduction of carbohydrate and fat intake is recommended to avoid these complications [43].

\subsection{Limitations and Strengths}

This study has some limitations. First, the cross-sectional design did not allow us to establish causality among the associated factors and the nutritional deficiency biomarkers in the study sample. Second, because it was an analysis of a secondary database, it was not possible to include minerals and other vitamins that could be relevant as nutritional deficiency biomarkers according to previous studies. Despite these limitations, to our knowledge, this study represents the first in Peru and one of the first in Latin America to evaluate the factors associated with nutritional deficiency biomarkers in patients who are candidates for bariatric surgery. According to the literature, this group is of special interest because although the nutritional deficit could be greater after surgery, if the patient already has this condition before surgery, it could be aggravated after the intervention. As such, it is important to act in a timely manner to avoid greater consequences. In addition, compared to developed countries, the Peruvian population is probably at greater risk [18]. The results allow the identification of modifiable and non-modifiable markers for the development of pre-surgical strategies that can be implemented to avoid adverse outcomes after surgery. 


\section{Conclusions}

Nutritional deficiency biomarkers were associated with sociodemographic, anthropometric and laboratory factors in patients who were candidates for bariatric surgery in Peru. This deficit can increase the risk of adverse outcomes and complications after bariatric surgery. Pre-surgical interventions aimed at reducing nutritional complications following surgery are needed in patients undergoing bariatric surgery.

Author Contributions: Conceptualization, A.R.-M., R.N.M.-R., G.C.-S., F.S.P.-M., D.U.-P., G.S.-S. and C.J.T.-H.; methodology, D.U.-P. and C.J.T.-H.; formal analysis, D.U.-P. and C.J.T.-H.; writing-original draft, A.R.-M., R.N.M.-R., G.C.-S., F.S.P.-M., D.U.-P., G.S.-S. and C.J.T.-H.; writing-review and editing, A.R.-M., R.N.M.-R., G.C.-S., F.S.P.-M., D.U.-P., G.S.-S. and C.J.T.-H. All authors have read and agreed to the published version of the manuscript.

Funding: This research received no external funding.

Institutional Review Board Statement: The study was conducted according to the guidelines of the Declaration of Helsinki, and was approved by the Institutional Review Board of the Clínica Avendaño (CIEI-Avendaño).

Informed Consent Statement: We performed a secondary data analysis, and the study database was anonymized, then, participant informed consent from the subjects involved in the study was not required.

Data Availability Statement: The datasets used to carry out this article could be available on reasonable request to the corresponding author.

Conflicts of Interest: The authors declare no conflict of interest.

\section{References}

1. World Health Organization (WHO). Obesidad y Sobrepeso [Internet]. WHO. 2020. Available online: https://www.who.int/es/ news-room/fact-sheets/detail/obesity-and-overweight (accessed on 27 April 2021).

2. Jiwani, S.S.; Carrillo-Larco, R.M.; Hernández-Vásquez, A.; Barrientos-Gutiérrez, T.; Basto-Abreu, A.; Gutierrez, L.; Irazola, V.; Nieto-Martínez, R.; Nunes, B.P.; Parra, D.C.; et al. The shift of obesity burden by socioeconomic status between 1998 and 2017 in Latin America and the Caribbean: A cross-sectional series study. Lancet Glob. Health 2019, 7, e1644-e1654. [CrossRef]

3. Monteiro, C.A.; Conde, W.L.; Lu, B.; Popkin, B.M. Obesity and inequities in health in the developing world. Int. J. Obes. 2004, 28, 1181-1186. [CrossRef]

4. Wolfe Bruce, M.; Elizave, R.H.E.; Kvach, T. Treatment of Obesity: Weight Loss and Bariatric Surgery Bruce. Physiol. Behav. 2018, 176, 139-148. [CrossRef]

5. Angrisani, L.; Santonicola, A.; Iovino, P.; Vitiello, A.; Higa, K.; Himpens, J.; Buchwald, H.; Scopinaro, N. IFSO Worldwide Survey 2016: Primary, Endoluminal, and Revisional Procedures. Obes. Surg. 2018, 28, 3783-3794. [CrossRef]

6. Barr, M.L.; Tabone, L.E.; Cox, S.J.; Brode, C.; Szoka, N.; Olfert, I.M.; Davisson, L.; Olfert, M.D. Bariatric Surgery Outcomes in Appalachia Influenced by Surgery Type, Diabetes, and Depression. Obes. Surg. 2019, 29, 1222-1228. [CrossRef] [PubMed]

7. Lim, R.; Beekley, A.; Johnson, D.C.; Davis, K.A. Early and late complications of bariatric operation. Trauma Surg. Acute Care Open 2018, 3, e000219. [CrossRef] [PubMed]

8. Lupoli, R.; Lembo, E.; Saldalamacchia, G.; Kesia, C.; Angrisani, L.; Capaldo, B. Bariatric surgery and long-term nutritional issues. World J. Diabetes 2017, 8, 26-32. [CrossRef] [PubMed]

9. Aarts, E.O.; Van Wageningen, B.; Janssen, I.M.C.; Berends, F.J. Prevalence of anemia and related deficiencies in the first year following laparoscopic gastric bypass for morbid obesity. J. Obes. 2012, 2012, 193705. [CrossRef]

10. Avgerinos, D.V.; Llaguna, O.H.; Seigerman, M.; Lefkowitz, A.J.; Leitman, I.M. Incidence and risk factors for the development of anemia following gastric bypass surgery. World J. Gastroenterol. 2010, 16, 1867-1870. [CrossRef] [PubMed]

11. Von Drygalski, A.; Andris, D.A.; Nuttleman, P.R.; Jackson, S.; Klein, J.; Wallace, J.R. Anemia after bariatric surgery cannot be explained by iron deficiency alone: Results of a large cohort study. Surg. Obes. Relat. Dis. 2011, 7, 151-156. [CrossRef]

12. Brolin, R.E.; Gorman, J.H.; Gorman, R.C.; Petschenik, A.J.; Bradley, L.J.; Kenler, H.A.; Cody, R.P. Are Vitamin B12 and Folate Deficiency Clinically Important after Roux-en-Y Gastric Bypass? J. Gastrointest. Surg. 1998, 2, 436-442. [CrossRef]

13. Avinoah, E.; Ovnat, A.; Charuzi, I. Nutritional status seven years after Roux-en-Y gastric bypass surgery. Surgery 1992, 111, 137-142. Available online: https:/ / europepmc.org/article/med/1736382 (accessed on 16 May 2021). [PubMed]

14. Al-Mutawa, A.; Anderson, A.K.; Alsabah, S.; Al-Mutawa, M. Nutritional status of bariatric surgery candidates. Nutrients 2018, 10, 67. [CrossRef] [PubMed] 
15. Wolf, E.; Utech, M.; Stehle, P.; Büsing, M.; Stoffel-Wagner, B.; Ellinger, S. Preoperative micronutrient status in morbidly obese patients before undergoing bariatric surgery: Results of a cross-sectional study. Surg. Obes. Relat. Dis. 2015, 11, 1157-1163. [CrossRef] [PubMed]

16. De Luis, D.A.; Pacheco, D.; Izaola, O.; Terroba, M.C.; Cuellar, L.; Cabezas, G. Micronutrient status in morbidly obese women before bariatric surgery. Surg. Obes. Relat. Dis. 2013, 9, 323-327. [CrossRef]

17. Tan, B.C.; Park, Y.S.; Won, Y.; Lee, S.; Kang, S.H.; Ahn, S.H.; Park, D.J.; Kim, H.H. Preoperative Nutritional Deficiencies in Bariatric Surgery Candidates in Korea. Obes. Surg. 2021, 31, 2660-2668. [CrossRef]

18. Roust, L.R.; Dibaise, J.K. Nutrient deficiencies prior to bariatric surgery. Curr. Opin. Clin. Nutr. Metab. Care 2017, 20, 138-144. [CrossRef]

19. Sánchez, A.; Rojas, P.; Basfi-fer, K.; Carrasco, F.; Inostroza, J.; Codoceo, J. Micronutrient Deficiencies in Morbidly Obese Women Prior to Bariatric Surgery. Obes. Surg. 2016, 26, 361-368. [CrossRef]

20. Toro-Huamanchumo, C.J.; Morán-Mariños, C.; Salazar-Alarcon, J.L.; Barros-Sevillano, S.; Huamanchumo-Suyon, M.E.; SalinasSedo, G. Latin American Research on Bariatric Surgery: A Bibliometric Study. Obes. Surg. 2021, 31, 1869-1876. [CrossRef]

21. Coupaye, M.; Puchaux, K.; Bogard, C.; Msika, S.; Jouet, P.; Clerici, C. Nutritional Consequences of Adjustable Gastric Banding and Gastric Bypass: A 1-year Prospective Study. Obes. Surg. 2008, 19, 56-65. [CrossRef]

22. Krzizek, E.-C.; Brix, J.M.; Thilo Herz, C.; Kopp, H.P.; Schernthaner, G.-H.; Schernthaner, G. Prevalence of Micronutrient Deficiency in Patients with Morbid Obesity Before Bariatric Surgery. Obes. Surg. 2017, 28, 643-648. [CrossRef]

23. Montastier, E.; Chalret du Rieu, M.; Tuyeras, G.; Ritz, P. Long-term nutritional follow-up post bariatric surgery. Curr. Opin. Clin. Nutr. Metab. Care 2018, 21, 388-393. [CrossRef] [PubMed]

24. Ziegler, O.; Sirveaux, M.A.; Brunaud, L.; Reibel, N.; Quilliot, D. Medical follow up after bariatric surgery: Nutritional and drug issues General recommendations for the prevention and treatment of nutritional deficiencies. Diabetes Metab. 2009, 35 Pt II, 544-557. [CrossRef]

25. Poitou Bernert, C.; Ciangura, C.; Coupaye, M.; Czernichow, S.; Bouillot, J.L.; Basdevant, A. Nutritional deficiency after gastric bypass: Diagnosis, prevention and treatment. Diabetes Metab. 2007, 33, 13-24. [CrossRef] [PubMed]

26. Alexandrou, A.; Armeni, E.; Kouskouni, E.; Tsoka, E.; Diamantis, T.; Lambrinoudaki, I. Cross-sectional long-term micronutrient deficiencies after sleeve gastrectomy versus Roux-en-Y gastric bypass: A pilot study. Surg. Obes. Relat. Dis. 2014, 10, 262-268. [CrossRef]

27. Kwon, Y.; Kim, H.J.; Lo Menzo, E.; Park, S.; Szomstein, S.; Rosenthal, R.J. Anemia, iron and vitamin B12 deficiencies after sleeve gastrectomy compared to Roux-en-Y gastric bypass: A meta-analysis. Surg. Obes. Relat. Dis. 2014, 10, 589-597. [CrossRef] [PubMed]

28. Lefebvre, P.; Letois, F.; Sultan, A.; Nocca, D.; Mura, T.; Galtier, F. Nutrient deficiencies in patients with obesity considering bariatric surgery: A cross-sectional study. Surg. Obes. Relat. Dis. 2014, 10, 540-546. [CrossRef]

29. Ha, J.; Kwon, Y.; Kwon, J.W.; Kim, D.; Park, S.H.; Hwang, J. Micronutrient status in bariatric surgery patients receiving postoperative supplementation per guidelines: Insights from a systematic review and meta-analysis of longitudinal studies. Obes. Rev. 2021, 22, e13249. [CrossRef]

30. McLean, C.; Mocanu, V.; Birch, D.W.; Karmali, S.; Switzer, N.J. Hypoalbuminemia Predicts Serious Complications Following Elective Bariatric Surgery. Obes. Surg. 2021, 31, 4519-4527. [CrossRef]

31. Gomi, I.; Fukushima, H.; Shiraki, M.; Miwa, Y.; Ando, T.; Takai, K. Relationship between serum albumin level and aging in community-dwelling self-supported elderly population. J. Nutr. Sci. Vitaminol. (Tokyo) 2007, 53, 37-42. [CrossRef]

32. Chen, J.C.; Shen, C.Y.; Lee, W.J.; Tsai, P.L.; Lee, Y.C. Protein deficiency after gastric bypass: The role of common limb length in revision surgery. Surg. Obes. Relat. Dis. 2019, 15, 441-446. [CrossRef]

33. Cabrerizo, S.; Cuadras, D.; Gomez-Busto, F.; Artaza-Artabe, I.; Marín-Ciancas, F.; Malafarina, V. Serum albumin and health in older people: Review and meta analysis. Maturitas 2015, 81, 17-27. [CrossRef] [PubMed]

34. De Paris, F.G.C.; Padoin, A.V.; Mottin, C.C.; de Paris, M.F. Assessment of Changes in Body Composition During the First Postoperative Year After Bariatric Surgery. Obes. Surg. 2019, 29, 3054-3061. [CrossRef] [PubMed]

35. Wang, C.; Guan, B.; Yang, W.; Yang, J.; Cao, G.; Lee, S. Prevalence of electrolyte and nutritional deficiencies in Chinese bariatric surgery candidates. Surg. Obes. Relat. Dis. 2016, 12, 629-634. [CrossRef]

36. Mosli, R.H.; Mosli, H.H. Obesity and morbid obesity associated with higher odds of hypoalbuminemia in adults without liver disease or renal failure. Diabetes Metab. Syndr. Obes. Targets Ther. 2017, 10, 467-472. [CrossRef]

37. Pellegrini, M.; Rahimi, F.; Boschetti, S.; Devecchi, A.; De Francesco, A.; Mancino, M.V.; Toppino, M.; Morino, M.; Fanni, G.; Ponzo, V.; et al. Pre-operative micronutrient deficiencies in patients with severe obesity candidates for bariatric surgery. J. Endocrinol. Investig. 2020, 44, 1413-1423. [CrossRef] [PubMed]

38. Blume, C.A.; Boni, C.C.; Casagrande, D.S.; Rizzolli, J.; Padoin, A.V.; Mottin, C.C. Nutritional profile of patients before and after Roux-en-Y gastric bypass: 3-year follow-up. Obes. Surg. 2012, 22, 1676-1685. [CrossRef]

39. Csendes, J.A.; Papapietro, V.K.; Burgos, L.A.; Lanzarini, S.E.; Canobra, L.M. Results of gastric bypass for morbid obesity after a follow up of seven to 10 years. Rev. Med. Chile 2011, 139, 1414-1420.

40. Galata, C.; Busse, L.; Birgin, E.; Weiß, C.; Hardt, J.; Reißfelder, C.; Otto, M. Role of Albumin as a Nutritional and Prognostic Marker in Elective Intestinal Surgery. Can. J. Gastroenterol. Hepatol. 2020, 2020, 7028216. [CrossRef]

41. Keller, U. Nutritional laboratory markers in malnutrition. J. Clin. Med. 2019, 8, 775. [CrossRef] 
42. Ben-Porat, T.; Elazary, R.; Yuval, J.B.; Wieder, A.; Khalaileh, A.; Weiss, R. Nutritional deficiencies after sleeve gastrectomy: Can they be predicted preoperatively? Surg. Obes. Relat. Dis. 2015, 11, 1029-1036. [CrossRef] [PubMed]

43. Bettini, S.; Belligoli, A.; Fabris, R.; Busetto, L. Diet approach before and after bariatric surgery. Rev. Endocr. Metab. Disord. 2020, 21, 297-306. [CrossRef] [PubMed] 